\title{
A novel mouse model of PMS2 founder mutation that causes mismatch repair defect due to aberrant splicing
}

Kajal Biswas ${ }^{1}$, Martin Couillard ${ }^{2}$, Luca Cavallone ${ }^{2}$, Sandra Burkett ${ }^{1}{ }^{1}$, Stacey Stauffer ${ }^{1}$, Betty K. Martin ${ }^{1,3}$, Eileen Southon ${ }^{1,3}$, Susan Reid ${ }^{1}$, Teri M. Plona ${ }^{4}$, Ryan N. Baugher ${ }^{4}$, Stephanie D. Mellott ${ }^{4}$, Kristen M. Pike (D) ${ }^{4}$, Mary E. Albaugh ${ }^{1,3}$, Chelsea Maedler-Kron $^{5}$, Nancy Hamel ${ }^{6,7}$, Lino Tessarollo ${ }^{1}$, Victoria Marcus ${ }^{5}$, William D. Foulkes $\mathbb{( D}^{2,6,7,8,9}$ and Shyam K. Sharan (D) ${ }^{1 凶}$

This is a U.S. government work and not under copyright protection in the U.S.; foreign copyright protection may apply 2021

Hereditary non-polyposis colorectal cancer, now known as Lynch syndrome (LS) is one of the most common cancer predisposition syndromes and is caused by germline pathogenic variants (GPVs) in DNA mismatch repair (MMR) genes. A common founder GPV in PMS2 in the Canadian Inuit population, NM_000535.5: c.2002A>G, leads to a benign missense (p.1668V) but also acts as a de novo splice site that creates a 5 bp deletion resulting in a truncated protein $\left(p .1668^{*}\right)$. Individuals homozygous for this GPV are predisposed to atypical constitutional MMR deficiency with a delayed onset of first primary malignancy. We have generated mice with an equivalent germline mutation (Pms2c.1993A>G) and demonstrate that it results in a splicing defect similar to those observed in humans. Homozygous mutant mice are viable like the Pms2 null mice. However, unlike the Pms2 null mice, these mutant mice are fertile, like humans homozygous for this variant. Furthermore, these mice exhibit a significant increase in microsatellite instability and intestinal adenomas on an Apc mutant background. Rectification of the splicing defect in human and murine fibroblasts using antisense morpholinos suggests that this novel mouse model can be valuable in evaluating the efficacy aimed at targeting the splicing defect in PMS2 that is highly prevalent among the Canadian Inuits.

Cell Death and Disease (2021)12:838; https://doi.org/10.1038/s41419-021-04130-8

\section{INTRODUCTION}

Pathogenic variants in the DNA mismatch repair (MMR) genes such as, MLH1, MSH2, PMS2, and MSH6 are associated with various human malignancies [1, 2]. Bi-allelic GPVs in MMR genes leads to a severe phenotype, constitutional MMR deficiency (CMMRD), that is characterized by early onset of leukemia/ lymphoma, colorectal/gastrointestinal tumors, brain tumors, and rhabdomyosarcoma [3]. Mono-allelic GPVs in MMR genes predisposes individuals to hereditary non-polyposis colorectal cancer (HNPCC), better known now as Lynch syndrome (LS) [4]. The mismatch repair (MMR) protein PMS2 (Post-meiotic segregation increased 2) interacts with another MMR protein MLH1 (MutL Homolog 1) and the MLH1-PMS2 heterodimer plays a central role in post-replicative DNA mismatch repair [5]. While mutations in mismatch repair genes $\mathrm{MLH} 1$ and $\mathrm{MSH} 2$ are more prevalent (42-50\% for MLH1 and 33-39\% for MSH2), PMS2 mutations are less frequent $(<7 \%)$ in families with LS [4]. The low penetrance of PMS2 in cancer is possibly due to the presence of homolog protein MLH3 which is able to bind MLH1 and partially function in MMR $[6,7]$. Tumors with deficiency in MMR genes display a molecular phenotype characterized by genomic instability of several microsatellite repeats present throughout the genome and is referred to as microsatellite instability (MSI) [8].

A number of unique mutations have been identified in various MMR genes, including several variants of uncertain clinical significance that are listed in InSiGHT database (https://www. insight-group.org/variants/databases/). One of the most frequently occurring mutations in PMS2 is a founder GPV found in the Inuit population of Nunavik, Quebec, Canada [9]. This GPV in exon 11 of PMS2 (NM_000535.5:c.2002A>G, (p.1668V)) generates a de novo splice site that competes with the authentic site, resulting in aberrant splicing and consequently deletion of five bases from exon 11 at the exon 11-12 junction in the mRNA and is predicted to generate a truncated protein [9]. Interestingly, although the variant is limited to Nunavik and the western coastline of Hudson Bay, it is predicted to be present in 1 in 16 Inuits. Surprisingly, in spite of the lack of full-length protein in homozygous individuals, the GPV results in an attenuated form of both CMMRD in homozygous state and LS in heterozygotes. The median age of first primary cancer diagnosis in homozygotes is 22 years whereas the median age for most CMMRD and LS patients with truncating mutations is 8 years [9]. Presence of residual full-length protein in patients with homozygous PMS2 c.2002A $>$ G mutation is predicted

\footnotetext{
${ }^{1}$ Mouse Cancer Genetics Program, Center for Cancer Research, National Cancer Institute, National Institutes of Health, Frederick, MD, USA. ${ }^{2}$ The Lady Davis Institute of the Jewish General Hospital, McGill University, Montreal, QC, Canada. ${ }^{3}$ Leidos Biomedical Research, Inc. Frederick National Laboratory for Cancer Research, Frederick, MD 21702, USA. ${ }^{4}$ CLIA Molecular Diagnostics Laboratory, Leidos Biomedical Research, Inc. Frederick National Laboratory for Cancer Research, Frederick, MD, USA. ${ }^{5}$ Department of Pathology, McGill University, Montreal, QC, Canada. ${ }^{6}$ Department of Oncology, McGill University, Montreal, QC, Canada. ${ }^{7}$ Department of Human Genetics, McGill University, Montreal, QC, Canada.

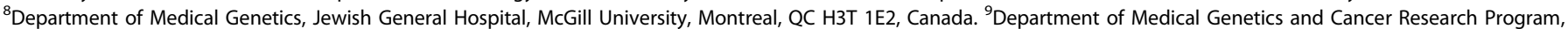

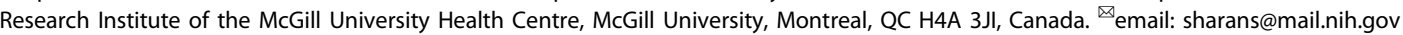
Edited by Rami Aqeilan
}

Received: 3 May 2021 Revised: 10 August 2021 Accepted: 18 August 2021

Published online: 06 September 2021 
to contribute to the attenuated phenotype in these patients compared to the typical CMMRD phenotype [9].

A number of mouse models of various MMR genes have been generated [10]. Pms2-null mice have been generated by deleting exon 2 [11]. Homozygous mutant $\left(P m s 2^{k o / k o}\right)$ mice were found to be viable but showed an increase in microsatellite instability and developed lymphomas and sarcomas. These mice also exhibited higher incidence of base substitutions as well as small insertions and deletions that lead to frameshift mutations [11-14]. Although these mice did not exhibit increased intestinal tumor susceptibility, a significant increase in adenoma formation in the small intestine and colon was observed on a $\operatorname{Apc}^{\text {Min }}$ (a single point mutation in murine Adenomatous polyposis coli, Apc) mutant background [12, 15]. APC functions as a housekeeper of cellular proliferation whereas the MMR genes are considered as caretaker genes and directly inhibits the promotion of tumor growth. APC mutations can be detected both in familial adenomatous polyposis (FAP) and non-FAP tumors including HNPCC and sporadic colorectal cancer. It had been reported that colorectal cancers with and without defect in MMR genes involve different genes including $A P C$, though defective MMR is considered to be the primary event in HNPCC $[16,17]$. Endonuclease-deficient (Pms2 $\left.2^{E 702 K / E 702 K}\right)$ knock-in mouse exhibited a higher level of genomic mutation rate and class switch recombination with increased incidences of lymphomas but failed to show an increased level of intestinal tumor formation. Unlike $P m s 2^{k o / k o}$ mice, $P m s 2^{\text {E702K/E702K }}$ male mice are fertile without any defect in spermatogenesis indicating that the endonuclease function of PMS2 is dispensable for spermatogenesis [18].

Given the high prevalence of the PMS2 c.2002A >G variant among Inuits, generation of a mouse model that mimics this mutation would be a valuable tool in efforts to prevent the early onset cancers occurring in an under-served Canadian population. Here, we describe the generation of a knock-in mouse model of Pms2 c.1993A>G that is the murine equivalent of the PMS2-founder mutation. As observed in humans homozygous for the GPV, Pms2 transcripts in the mutant mice showed skipping of the last five bases of exon 11. This is predicted to result in premature truncation of PMS2 protein at codon 1665. These mice exhibited no overt phenotype. However, on a Apc $^{\text {tmlRak }}$ (a chain-terminating mutation at codon 1638 in exon 15 of Apc) mutant background, Pms $2^{\text {c.1993A }>G / c .1993 A>G}$ mice showed a significant increase in intestinal adenoma formation, which makes them a useful model to test the efficacy of therapeutics designed to suppress aberrant splicing in heterozygotes.

\section{RESULTS}

\section{Generation of Pms2 c.1993A>G/c.1993A>G mice}

To generate a mouse model for PMS2 c.2002A $>G$ mutation, we first analyzed the corresponding Pms2 c.1993A >G mutation using the Splice Site analysis tool of Human Splicing Finder (http://www.umd. be/HSF/HSF.shtml). In silico prediction tool identifies generation of a stronger 5'splice site motif (GAGgttaag) due to c.1993A>G mutation compared to the authentic splice site (TAGgtactg) [score is 91.28 for the newly generated site and 74.96 for the authentic site]. This is in agreement with the effect of the corresponding mutation in humans [9]. Analysis of the genomic sequence using ESEFinder (http:// krainer01.cshl.edu/tools/ESE2/) also identifies a new binding site of the splicing factor SF2/ASF in both human and mouse genes with the mutation (Supplementary Fig. 1) [19]. Based on these observations, we predicted that Pms2 c.1993A $>$ G may result in a splicing defect in mice similar to the $P M S 2$ c.2002A $>G$ mutation in humans.

We used a conventional embryonic stem (ES)-based genetargeting approach to introduce Pms2 c.1993A $>$ G into exon 11 and confirmed correct targeting by Southern hybridization and sequencing (Supplementary Fig. 2). We used targeted ES cells to generate heterozygous Pms2 $2^{\text {c.1993A }>\text { G-Neo/ }+}$ mice. We excised the Neo cassette by crossing these mice with $\beta$-actin Cre transgenic mice to obtain Pms $2^{c .1993 A>G /+}$ (referred to as $P m s 2^{k i /+}$ ) heterozygous mice. Homozygous Pms2 c.1993A>G/c.1993A>G (referred to as $P m s 2^{k i / k i}$ ) were obtained at the expected Mendelian ratio (Supplementary Table 1). Sanger sequencing of RT-PCR products from the colon of $P m s 2^{k i / k i}$ mice showed only one transcript with a deletion of the last five base pairs of exon 11 (Fig. 1A, B). Sanger sequencing of cDNA from $P m s 2^{k i /+}$ mice showed mixed sequences in that region, indicating the use of two different splice sites in two alleles (Fig. 1A, B). The splicing defect is not tissue specific and all the tissues that were tested showed the use of the de novo splice site in $P m s 2^{k i / k i}$ mice (Fig. 1C). Deletion of five base pairs generate a stop codon at codon $665\left(1665^{*}\right)$. We also failed to detect the expression of any residual WT protein by western blot using splenic protein extract from Pms $2^{k i / k i}$ mice (Fig. 1D). This suggests that the majority of the protein generated in these mice is truncated protein. However, we cannot rule out the possibility that very low amount of full-length protein is expressed in these mice, which is undetectable by western blotting.

\section{Pms2 $2^{k i / k i}$ mice are fertile}

Pms2 null $\left(P m s 2^{k o / k o}\right)$ male mice are infertile with reduced testis size and abnormal mature sperm cells. Defective spermatogenesis in those mice is associated with depletion of spermatogenic cells in seminiferous tubules, and impairment in progression of prophase I of meiosis due to defective synapsis [11]. Strikingly, both male and female $P m s 2^{k i / k i}$ mice are fertile and produce litters of normal size. Testis size, histology and sperm count in Pms $2^{k i / k i}$ mice was similar to the Pms2 $2^{k i /+}$ littermates (Fig. 2A-D). Proper synapse in Pms $2^{k i / k i}$ mice indicates that the progression through meiotic prophase $I$ is normal in these mice (Fig. 2E). In spite of the lack of any apparent fertility problems or defects in meiotic progression in these mice, we failed to detect PMS2 protein in the testis of $P m s 2^{k i / k i}$ mice by western blotting (Fig. 2F). This suggests that the expression of functional PMS2 is highly reduced in these mice and beyond the level of detection by western blotting. However, the levels are sufficient to suppress the phenotypes observed in Pms2 null mice.

\section{Increased adenomatous polyp formation in Pms $2^{\mathbf{k i} / \mathbf{k}}$ mice}

We next examined the intestinal tract of 6 months old mice to determine if the depletion of PMS2 protein due to aberrant splicing has any effect on intestinal polyp formation. Previous studies have revealed that PMS2 deficiency has significant effect on intestinal adenoma formation only when it was combined with APC deficiency [15]. Therefore, we crossed our $P m s 2^{k i / k i}$ mice with $A p c^{\text {tmlRak/+ }}$ (for simplicity, referred to as $\mathrm{ApC}^{+/-}$) and generated $\mathrm{Pms}^{\mathrm{ki} /+} ; \mathrm{Apc}^{+/-}$and Pms2 $2^{\mathrm{ki} / k i} ; \mathrm{ApC}^{+/-}$mice [20]. Apc ${ }^{\text {tm } 1 \mathrm{Rak} /+}$ mice display a milder cancer phenotype and live longer compared to other Apc mutant strains, such as $A p c^{M i n}$ and $A p c^{\Delta 716}$ [20-23]. This property makes this mouse as an ideal model to study additional risk factors like MMR deficiency in intestinal tumorigenesis and has been used to study the roles of other MMR genes like MIh1, Msh2, Msh3, and Msh6 in intestinal tumorigenesis [24-26]. Intestinal polyp formation was compared at 6 months of age and 20 mice (10 males and 10 females) were examined in each group. In our facility, $\mathrm{Apc}^{+/-}$mice developed $1.7 \pm 2.05$ (mean \pm s.d) intestinal polyps whereas $P m s 2^{k i / k i} ; A p C^{+/-}$mice showed increased number of polyp formation $(7.7 \pm 4.9) \quad(P$ value $<0.0001)$ (Fig. 3A). In contrast, $P m s 2^{\mathrm{ki} /+} ; \mathrm{ApC}^{+/-}$mice did not show significant increase in polyp formation when compared to $\mathrm{Apc}^{+/-}$mice $(0.8 \pm 1.2 \mathrm{vs}$ $1.7 \pm 2.05$ with $P$ value 0.1246 ) (Fig. 3A). Pms 2 deficiency alone did not significantly increase polyp formation compared to WT mice ( $P$ value 0.1069 ) (Fig. 3A).

The polyps isolated are mostly $>2 \mathrm{~mm}$ in size and the size distribution among different genotypes have a similar pattern (for example 149/170 are $>2 \mathrm{~mm}$ in size for $\mathrm{Pms}^{\mathrm{ki} / k i} ; \mathrm{Apc}^{+/-}$mice and 31/ 37 are $>2 \mathrm{~mm}$ in size for $\mathrm{Apc}^{+/-}$mice) (Fig. 3B). Polyps were further 
analyzed histo-pathologically (Fig. 3C, D). Average number (per mice) of intestinal polyps that were adenomatous with high-grade and low-grade dysplasia are higher ( 0.76 and 0.33 respectively) compared to the similar pathology observed in $\mathrm{Apc}^{+/-}(0.15$ and 0.1 respectively) or $\mathrm{Pms}^{\mathrm{Ki/}+} ; \mathrm{Apc}^{+/-}(0.05$ and 0.1 respectively) (Fig. $3 \mathrm{C}$ and Supplementary Table 2). Five polyps of $P m s 2^{k i k i}$; $\mathrm{ApC}^{+/-}$mice progressed through adenocarcinoma formation (Fig. $3 \mathrm{C}$ and Supplementary Table 2). We have observed similar pathology of the polyps isolated from $\mathrm{ApC}^{+/-}$or $\mathrm{Pms} 2^{\mathrm{ki} / \mathrm{ki}} ; \mathrm{ApC}^{+/-}$mice indicating that PMS2 deficiency due to the splicing defect significantly increased the incidence of adenomatous polyp formation when combined with APC deficiency but did not alter the morphology of the polyps themselves (Fig. 3C and Supplementary Table 2) [27].

A

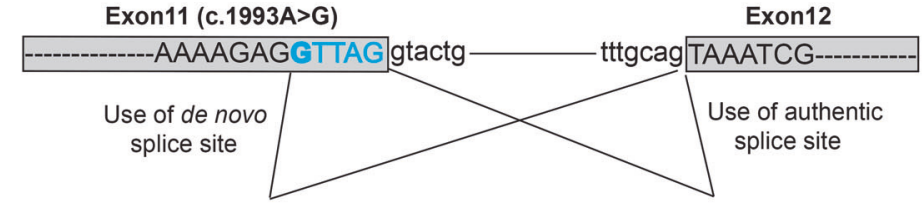

-AAAAGAGTAAATCG

(Skips last 5 bases of exon 11)

Truncated protein $\left(1665^{*}\right)$

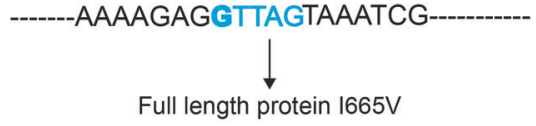

B

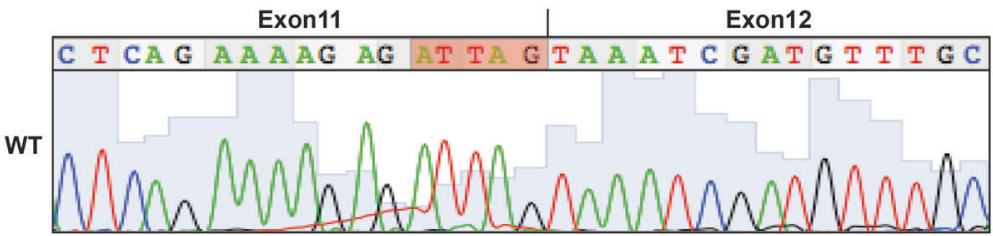

Exon11

Mixed (Exon11 and 12)
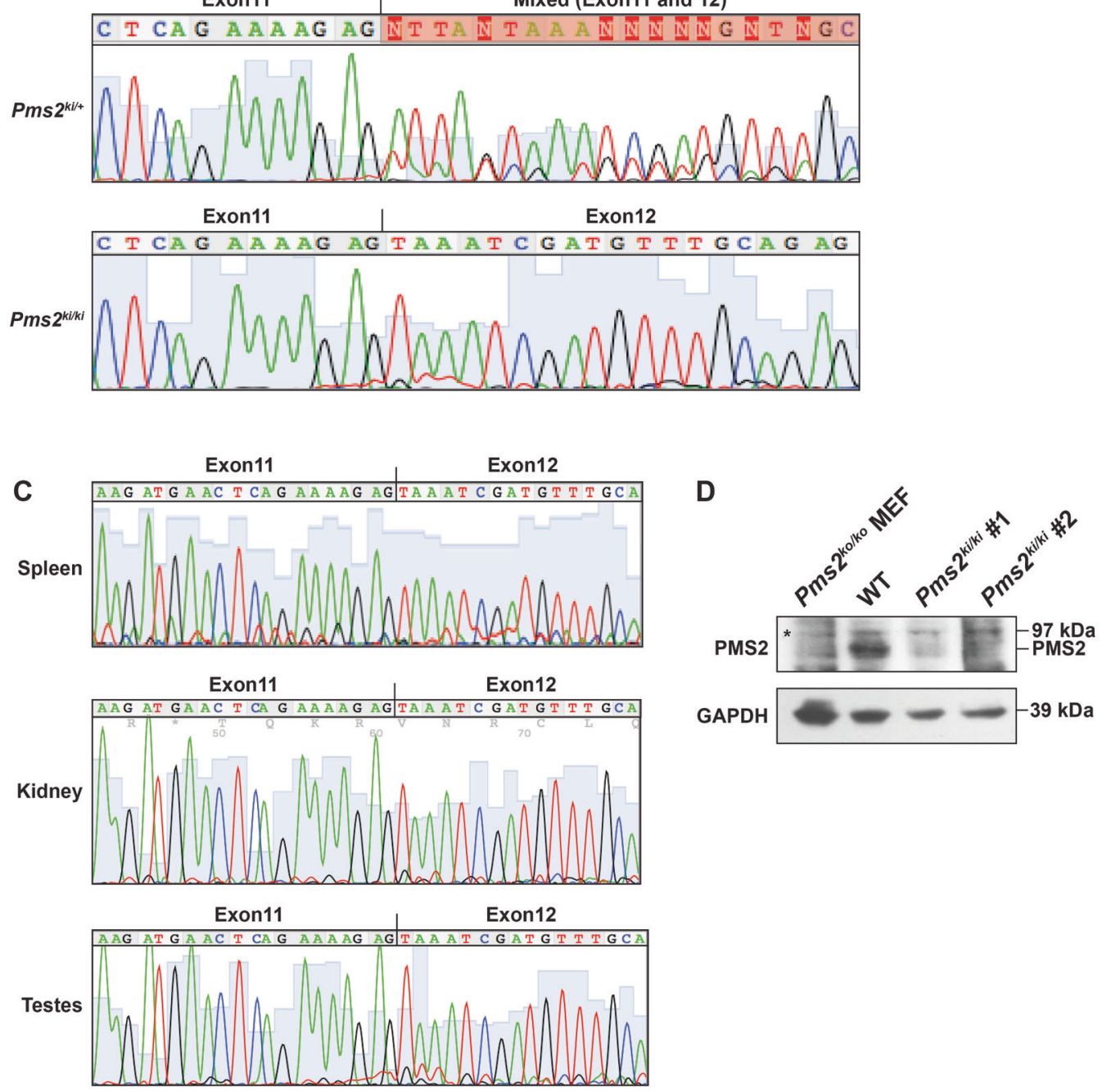
Fig. 1 Pms2 ${ }^{k i / k i}$ mice exhibit skipping of five bases of exon 11. A Schematic representation of splicing pattern due to $c .1993 \mathrm{~A}>\mathrm{G}$ mutation. Relevant exons are shown in box and intron as straight line. Exon sequences are in capital letters and intron sequences are in small letter. The mutation is in bold and the five base of exon 11 that are deleted in the transcript due to generation of new splice site are in blue. B Chromatogram showing the sequence of Pms 2 transcript from colon of wild type (WT), Pms $2^{k i /+}$ and Pms ${ }^{k / / k i}$ mice. Highlighted bases in WT chromatogram shows the region skipped due to c.1993A>G mutation. Transcript sequence from heterozygous mice showing mixed sequence is highlighted. C Pms2 transcript sequences from different tissues (spleen, kidney and testes) of Pms $2^{k i / k i}$ mice showing the deletion of last five bases of exon 11. D Expression of PMS2 protein in wild-type (WT) and Pms $2^{k i / k i}$ mice. Proteins were isolated from spleen of mice with indicated genotypes. Two independent Pms $2^{\mathrm{ki} / k i}$ mice were used and they are numbered as \#1 and \#2. Proteins isolated from immortalized mouse embryonic fibroblast of Pms $2^{\mathrm{ko} / \mathrm{ko}}$ (null) mice (127TAg) [ATCC; cat\# CRL-2817 ${ }^{\mathrm{TM}}$ ] was used as negative control. GAPDH was used as loading control. Asterisk designates non-specific band. Protein size markers are indicated on right side.

Microsatellite instability in adenomas isolated from $P m s 2^{k i / k i}$; $\mathrm{Apc}^{+/-}$mice

Microsatellite instability (MSI) is a hallmark for LS. Pms $2^{\text {ko/ko }}$ (homozygous for the null allele) mice showed MSI in the tumors, demonstrating an association between PMS2 loss and destabilized microsatellite sequences [11]. To examine MSI in the intestinal polyps obtained from our Pms2 mutant mice, we further evaluated 54 polyps collected from mice of different genotypes (Fig. 4A). We used four mononucleotide repeat markers, Bat24, Bat37, Bat59, and Bat64 for MSI analysis [28]. Among these four markers, Bat24, Bat37, and Bat59 are monomorphic and amplified $120 \mathrm{bp}, 149 \mathrm{bp}$, and $179 \mathrm{bp}$ allele respectively (Supplementary Fig. 3). Bat64 marker showed polymorphism and amplified three different alleles (136 bp, $162 \mathrm{bp}$, and $179 \mathrm{bp}$ ) in the WT mice (C57Bl6/129 mixed background) in our cohort (Supplementary Fig. 3). Due to polymorphisms observed at Bat64 locus in our WT background, we excluded the analysis of this marker for MSI. We observed MSI consistently at Bat37 and Bat59 marker in the polyps analyzed (Fig. 4). MSI of polyps at Bat37 marker revealed single repeat addition and at Bat59 marker revealed two repeats deletion compared to WT normal colon (Fig. 4A, B). We did not observe any MSI at Bat24 marker on the polyps analyzed compared to WT normal colon. Polyps that have showed MSI at Bat37 and Bat59 loci are all either Pms2 $2^{k i / k i}$ or Pms2 $2^{k / k i} ; \mathrm{Apc}^{+/-}$mice except one polyp from $\mathrm{Pms}^{\mathrm{ki} /+}$; $\mathrm{Apc}^{+/-}$mice that showed MSI at Bat37 marker (Fig. 4C). Our findings suggest that the adenomatous polyps with PMS2 deficiency have increased MSI, consistent with the phenotype previously reported in $P m s 2^{k o / k o}$ mice [11].

\section{Endonuclease activity in primary mouse embryonic fibroblasts isolated from Pms2 $2^{k i / k i}$ mice}

Endonuclease activity of PMS2 is important for its role in DNA repair and recombination. Mice defective in PMS2 endonuclease activity showed significant increase in genomic mutations and tumor incidence $[18,29]$. To determine the effect of Pms2 c.1993A>G mutation on the endonuclease activity, we tested nuclear extracts isolated from $P m s 2^{k i / k i}$ and WT MEF cells for their ability to repair G-T mismatches on heteroduplexes that contains also a single-stranded nick either $5^{\prime}$ or $3^{\prime}$ to the mismatched base. Nuclear extracts from immortalized $P m s 2^{k o / k o}$ MEF (127TAg, ATCC cat \# CRL-2817) was used as control. We failed to detect any MMR activity in Pms2 $2^{k i / k i}$ or Pms2 ${ }^{k o / k o}$ extracts, whereas WT nuclear extracts showed MMR activity (Fig. 4D). It demonstrates that the $P m s 2^{k i / k i}$ mice are defective in their endonuclease function and thus MMR function.

\section{Restoration of PMS2 full-length transcript using Antisense Morpholino Oligos}

Antisense oligonucleotide mediated restoration of splicing defect in mutations causing Duchene Muscular Dystrophy (DMD) has entered into clinic for most common DMD mutations [30]. In order to test if use of Antisense Morpholino Oligos (AMO) can restore the splicing defect of $P m s 2^{k i / k i}$ mice, we designed morpholinos to specifically block the splicing donor site created by the mutation while leaving the authentic site, located five base pairs away, uncovered and accessible to the splicing machinery (Fig. 5A). The morpholino $(10 \mu \mathrm{M})$ was then nucleofected into primary mouse embryonic fibroblasts derived from $P m s 2^{k i / k i}$ mouse embryos. Sanger sequencing of the RT-PCR product generated from the RNA of cells, $48 \mathrm{~h}$ after nucleofection of morpholinos showed that the designed morpholino could effectively block the de novo splice site generated due to Pms2 c.1993G>A mutation (Fig. 5B). In the chromatogram, it is clear that the last five base pairs from exon 11 is included in the transcript generated after use of morpholino in the cells homozygous for Pms2 c.1993G>A mutation (Fig. 5B, lower panel).

We next tested if these AMOs can be used to restore the expression of full-length PMS2 transcript in human fibroblasts derived from persons homozygous for the PMS2 c.2002A>G GPV. The impact of AMO treatment on PMS2 transcripts in treated fibroblasts was measured using quantitative PCR and gel electrophoresis as well as with pyrosequencing. Results show a marked increase in the relative and total amounts of full-length PMS2 transcript produced in treated cells (Fig. 6A, B and Supplementary Fig. 4). In addition, western blot analysis showed a clear increase in the amount of full-length PMS2 protein produced following AMO treatment (Fig. 6C), demonstrating that treatment is effective in partially restoring normal PMS2 expression in cells carrying the variant.

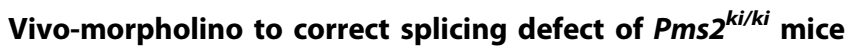
Morpholino oligomers attached to molecular transporters with eight guanidium head groups (Vivo-Morpholino) has been shown to correct targeted splicing errors in a wide variety of tissues including the small intestine [31]. Increased adenomatous polyp formation in the $P m s 2^{k i / k i}$ mice in combination with $A p c^{+1-}$ genotype indicates that increasing the amount of WT PMS2 transcript may attenuate this phenotype. Octa-guanidine linked morpholinos (vivo-morpholino) has been used previously to deliver efficiently in cardiac and skeletal muscles and improve dystrophin expression [32]. In an attempt to correct the splicing defect in Pms2 c. 1993A $>$ G allele, we have injected $P m s 2^{k i / k i}$ mice either with control or Pms2 specific vivo-morpholinos for 4 consecutive days. We delivered morpholinos using both intravenous $(12.5 \mathrm{mg} / \mathrm{kg}$ dose) and intraperitoneal ( $30 \mathrm{mg} / \mathrm{kg}$ dose) injections. On day 5 post-injection, we dissected the small intestine of these mice, extracted total RNA and performed RT-PCR. Sanger sequencing of the RT-PCR products failed to detect any restoration of authentic splice site (Supplementary Fig. 5). Our results suggested that the vivo-morpholinos failed to suppress splicing from the de novo splice site. The inability to suppress aberrant splicing in the small intestine is likely due to inefficient delivery of vivo-morpholinos to the small intestine. This remains to be a challenge and must be overcome by the development of novel approaches to deliver morpholinos to these organs in future.

\section{DISCUSSION}

Aberrant splicing of transcripts is well known to be responsible for a number of diseases, including cancer [33, 34]. These defects arise either due to a mutation in a splicing regulator, disruption of splice sites or activation of de novo splice sites. One such splice site variant, c.2002A $>$ G in PMS2 is associated with LS. It is a 

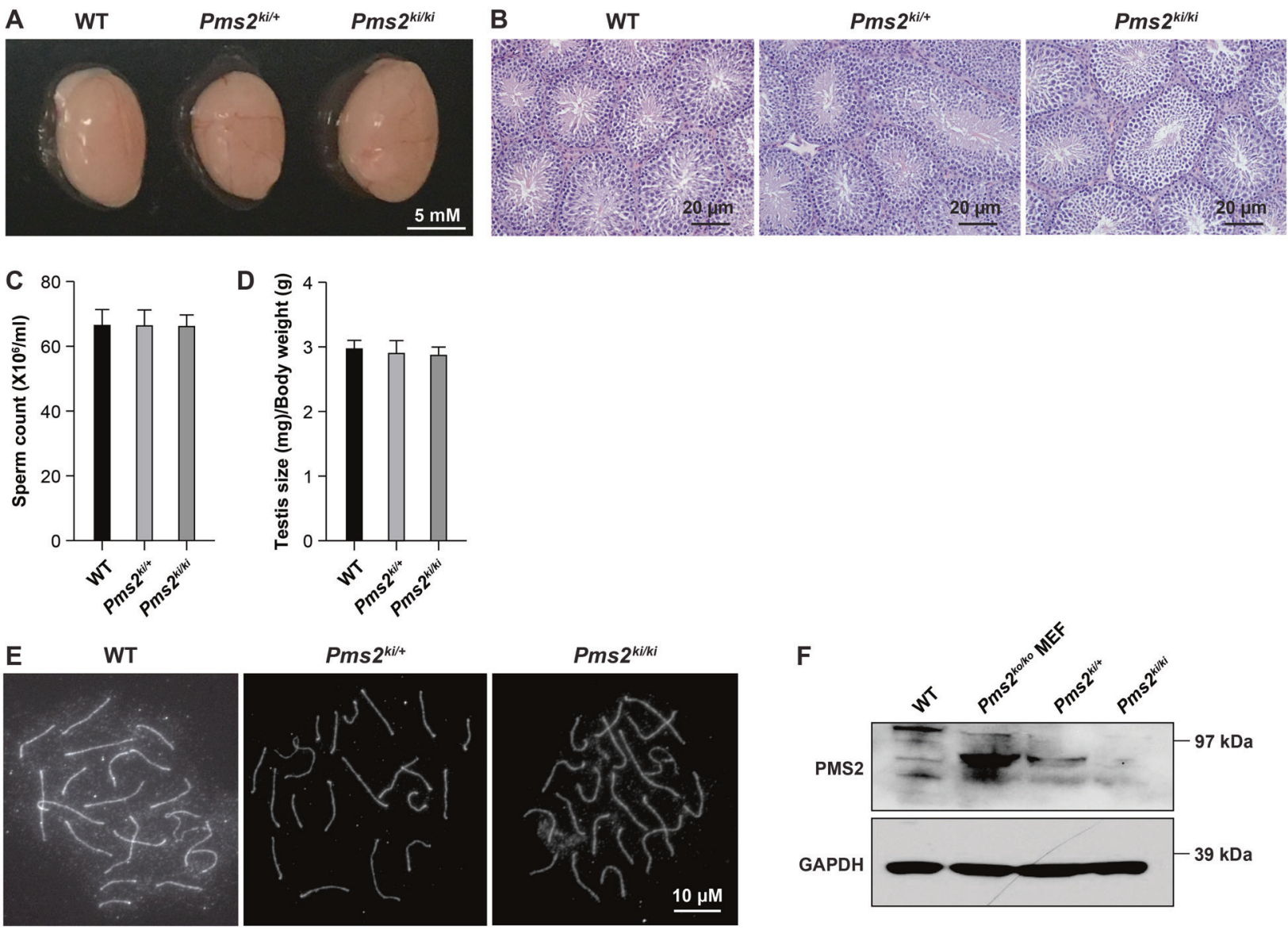

Fig. 2 Pms $2^{k i / k i}$ mice have normal testis morphology and histology, sperm count and meiotic progression. Testis morphology of $P m s 2^{k i / k i}$ mice: A Representative images of testis dissected from WT, $P m s 2^{k i /+}$ and $P m s 2^{k i / k i}$ mice. B H\&E staining of cross sections of testis from 8 weeks old WT, Pms $2^{k i /+}$ and Pms $2^{k i k i}$ mice. C Count of sperms isolated from epididymis of mice of different genotypes. D Comparison of testis sizes of 8 weeks old WT, $P m s 2^{k i /+}$ and $P m s 2^{k i / k i}$ mice. Average of five mice per genotype is shown. E Representative images of pachytene chromosomes stained with SYCP3 antibody from WT, Pms $2^{\mathrm{ki} /+}$ and $P m s 2^{\mathrm{ki} / k i}$ mice, indicating progression through prophase I. F Expression of PMS2 protein in testis of $P m s 2^{k i /+}$ and $P m s 2^{k i / k i}$ mice.

founder GPV in one population of Canadian Inuits [9]. The Pms2 mouse model we have generated is novel and, to the best of our knowledge, the first model with a point mutation in Pms2 that affects splicing. Mutant mice recapitulate some of the key phenotypes observed in PMS2 c.2002A>G homozygous individuals. In contrast to the infertility of male mice that are homozygous for the null allele $\left(P m s 2^{k o / k o}\right)$, males homozygous for the Pms2 c.1993A $>\mathrm{G}$ allele are fertile. PMS2 c.2002A $>\mathrm{G}$ homozygous male patients are fertile and have been confirmed to have had biological children $[9,11]$.

The precise cause of the difference in the fertility phenotype between the two mouse models is unclear. PMS2 has three important domains: N-terminal ATPase domain, an endonuclease domain located at C-terminus, and another C-terminal domain needed for heterodimerization with MLH1. Premature truncation of the mouse PMS2 protein $\left(1665^{*}\right)$ due to the de novo splice site generated by c.1993A $>\mathrm{G}$ mutation is expected to disrupt the MLH1 heterodimerization domain whereas the ATPase domain and endonuclease domains will remain intact. It has been shown in mouse models that PMS2 endonuclease and ATPase activities are dispensable for male meiosis and fertility $[18,35]$.

Heterodimerization domain of PMS2 is important for male fertility and MLH1 stabilization [11,35]. Despite the depletion of the full-length PMS2 protein to detectable levels in Pms $2^{\text {ki/ki }}$ testis, these mice are fertile. It is possible that these mice have a low amount of the full-length protein with $1665 \mathrm{~V}$ mutation encoded by full-length transcripts generated by using the authentic exon 11 donor splice site. Our hypothesis is supported by the presence of full-length transcript in homozygous PMS2 c.2002A $>G$ male patients, at levels that can be detected only by highly sensitive single molecule-based Polymerase colony assay [9]. It suggests that very low levels of PMS2 is sufficient for normal meiotic progression and spermatogenesis.

PMS2 deficiency in Pms $2^{\text {ko/ko }}$ mice was reported to increase the number of intestinal adenomas on a $A p c^{\mathrm{min} /+}$ background approximately three to four times relative to $\mathrm{ApC}^{\mathrm{min} /+} ; \mathrm{PMS}^{\mathrm{kol}}$ ${ }^{+}$mice [15]. Pms $2^{\mathrm{ko} /+}$ mice developed more $N$-methyl- $N$-nitrosourea (MNU) induced intestinal tumors compared to WT [36]. In this study, Pms $2^{k i / k i}$ mice in combination with heterozygous Apc mutation (chain-termination mutation in the 15 th exon, $\mathrm{Apc}^{+-}$) showed $\sim 4.5$ fold increase in intestinal polyp formation compared to $\mathrm{ApC}^{+/-}$or $\mathrm{Pms}^{\mathrm{ki} /+}$; $\mathrm{ApC}^{+/-}$mice. Intestinal adenomas that were $P m s 2^{k i / k i}$ also showed increased MSI, a hallmark of MMR deficiency.

Antisense oligonucleotides are among the most promising therapeutic candidates for such genetic diseases associated with splicing defects. Inducing alternate transcription by antisense oligonucleotides to bypass premature stop codon generated due to RNA mis-splicing can restore the gene function. It has been demonstrated that antisense morpholino oligonucleotides (AMO) can restore translational reading frames that were affected by splicing site mutations in mouse and dog models for Duchene muscular dystrophy (DMD) in vivo [37-40]. Morpholino based therapy for DMD has also now been approved by US Food and Drug administration as an exon-skipping drug [41]. Antisense 
A

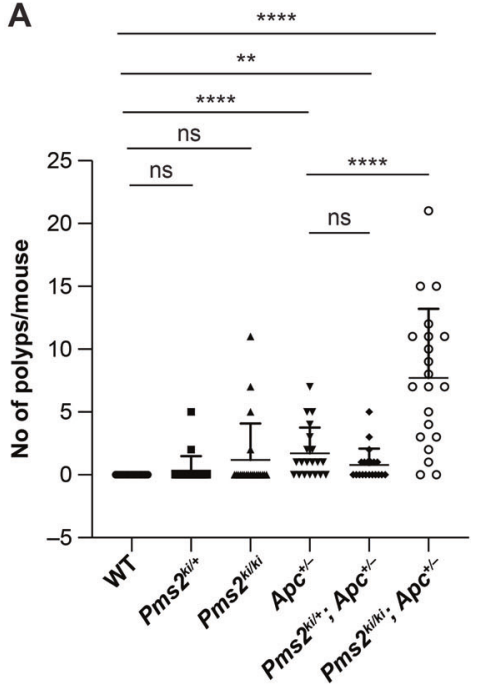

B

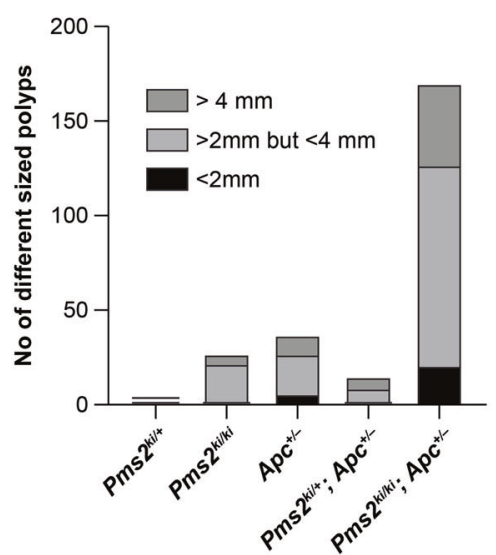

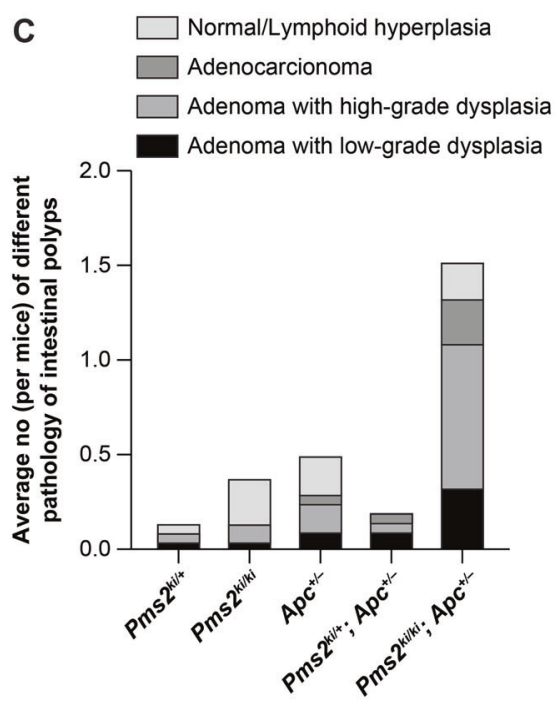

D

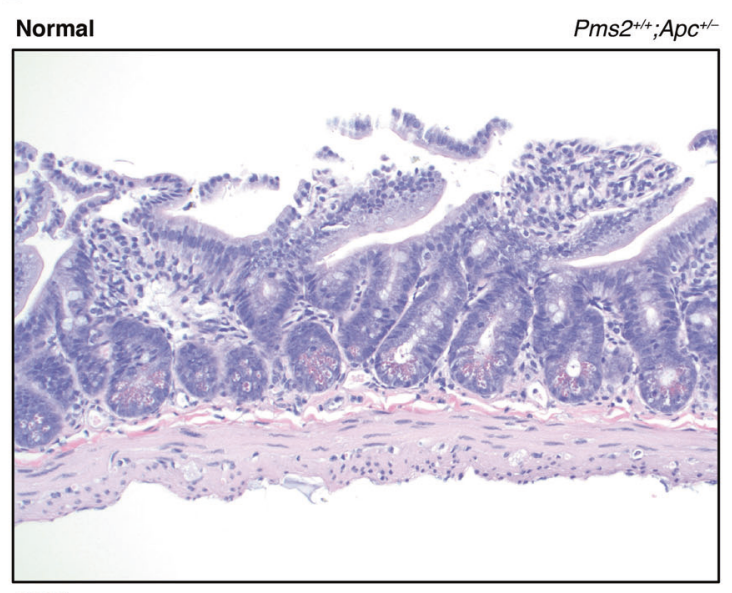

$200 X$

High grade hyperplasia

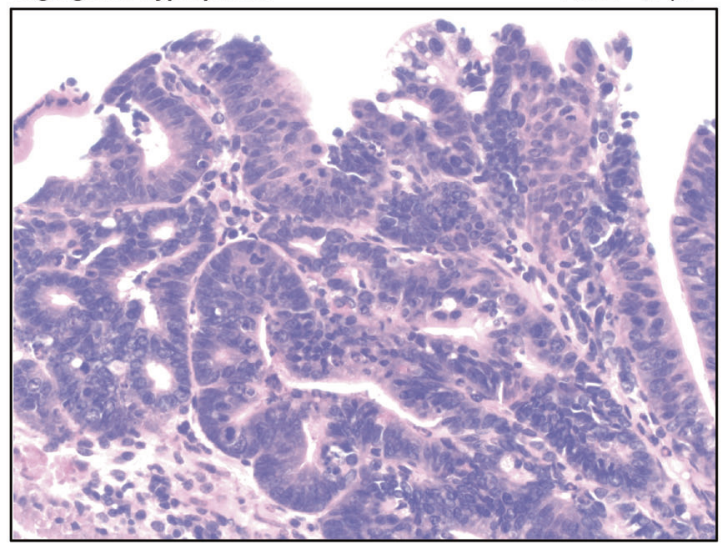

$400 \mathrm{X}$
Low grade hyperplasia

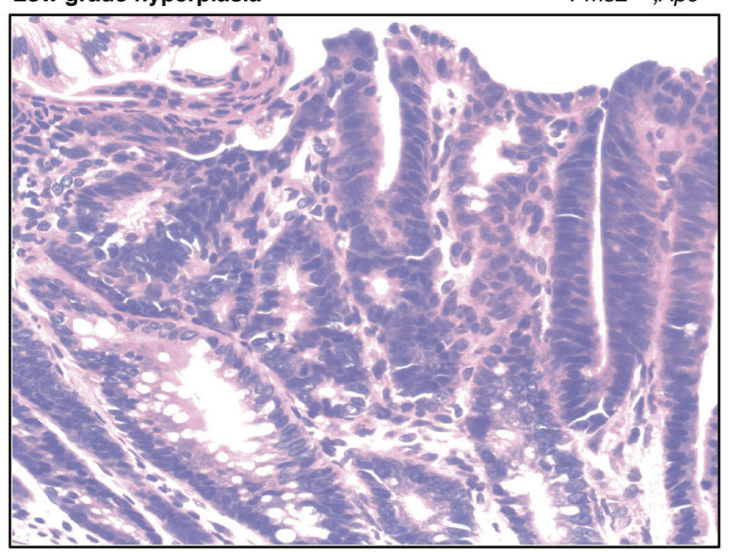

$400 X$

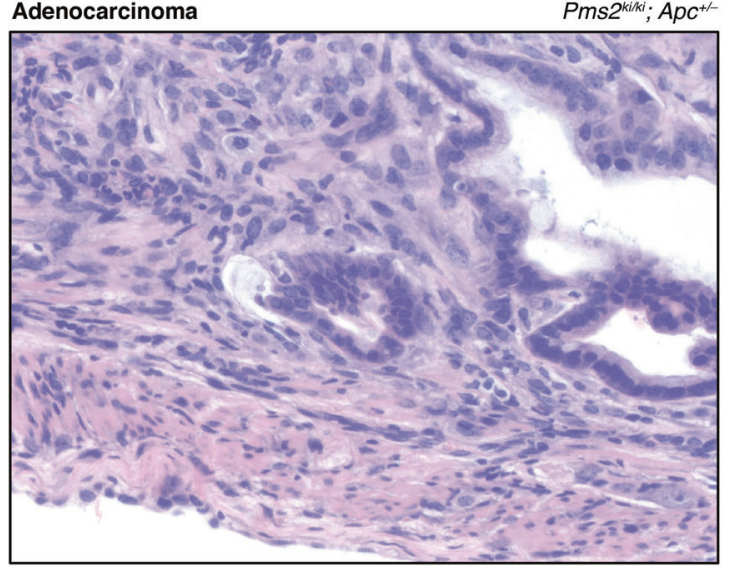

$400 \mathrm{X}$

Fig. 3 Effect of Pms2 c.1993A>G mutation on intestinal polyp formation on a $\mathrm{Apc}^{+/-}$mutant genetic background. A Numbers of intestinal polyps in 6 months old mice of different genotypes. For each group of genotypes 10 males and 10 females were included. Error bar shows mean \pm s.d. ${ }^{* * *} P$ value $<0.0001$ and ${ }^{* *} P$ value $<0.01$. ns is non-significant. $P$ values were calculated using Mann-Whitney test by Prism software. B Size distribution of intestinal polyps isolated from different genotypes. C Pathological distribution of intestinal polyps isolated from different genotypes. Average number was determined by dividing the total number of particular pathology found in each genotype with the number of mice studied in that group. D Representative images of different pathology (normal, low-grade hyperplasia, high-grade hyperplasia, and adenocarcinoma) of intestinal polyps. The genotypes are indicated on upper right corner and the magnification is indicated on lower left corner. 
A

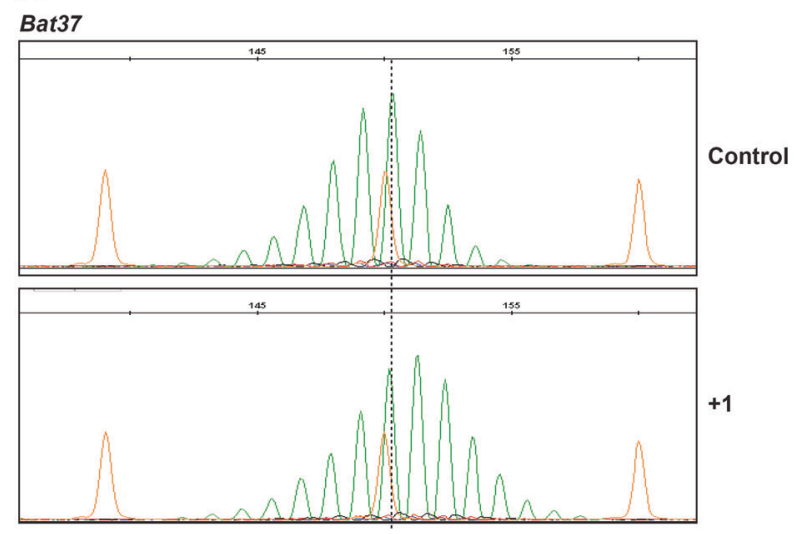

B

Bat59
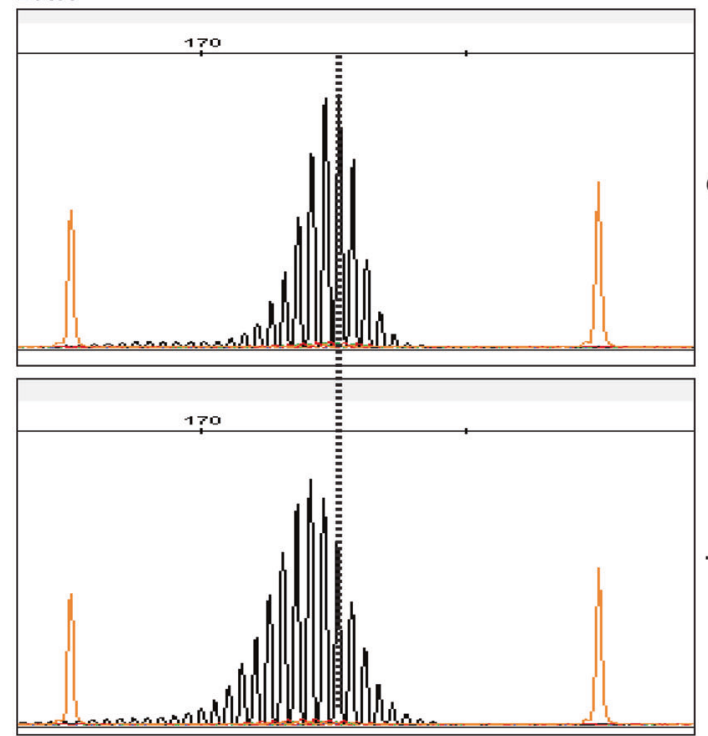

C

\begin{tabular}{|c|c|c|c|}
\hline Genotype & $\begin{array}{l}\text { No of polyp } \\
\text { analysed }\end{array}$ & $\begin{array}{l}\text { MSI at } \\
\text { Bat37 locus }\end{array}$ & $\begin{array}{l}\text { MSI at } \\
\text { Bat59 locus }\end{array}$ \\
\hline$P m s 2^{k i /+}$ & 2 & 0 & 0 \\
\hline$P m s 2^{k i / k i}$ & 6 & 4 & 6 \\
\hline$A p c^{+/}$ & 14 & 0 & 0 \\
\hline$P m s 2^{k i+} ; A p c^{+/-}$ & 10 & 1 & 0 \\
\hline$P m s 2^{k i / k i} ; A p c^{+/-}$ & 22 & 2 & 16 \\
\hline
\end{tabular}

Control

$-2$

D
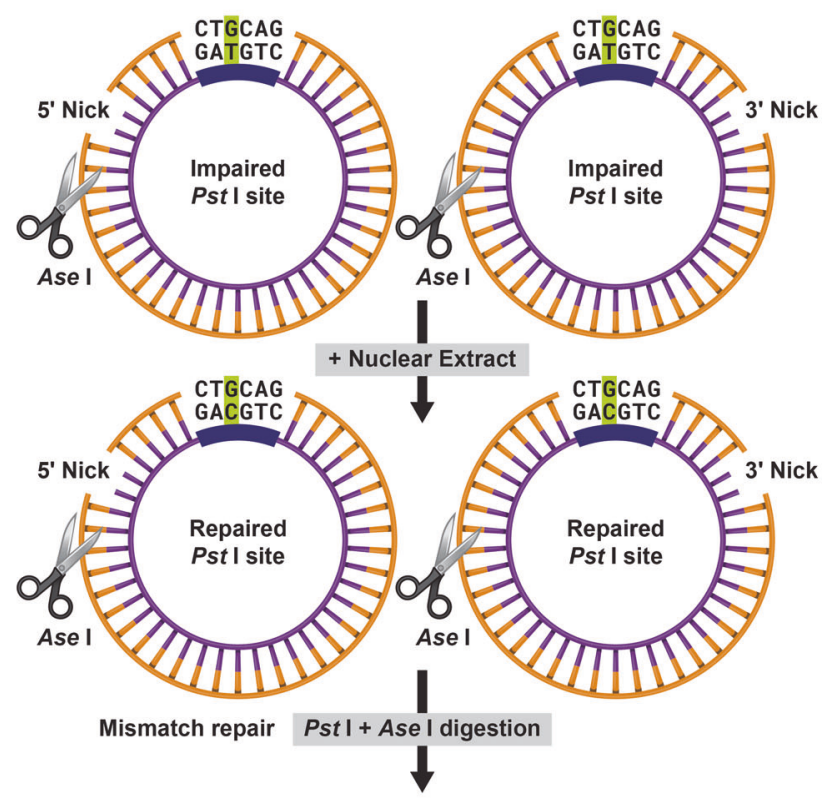

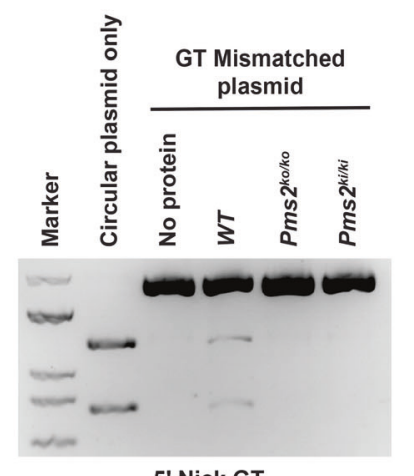

5' Nick GT

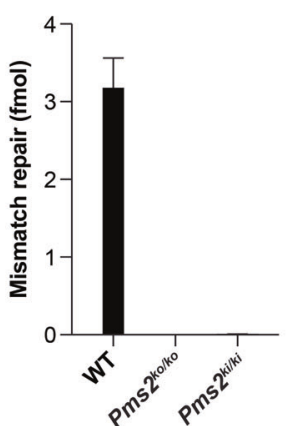

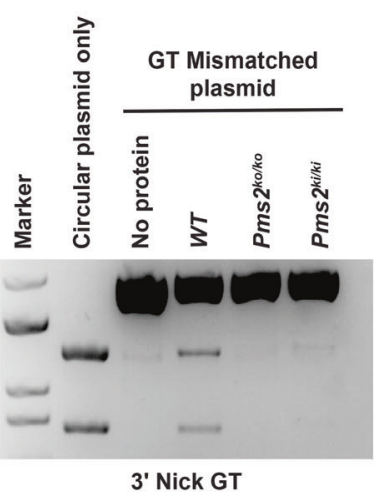

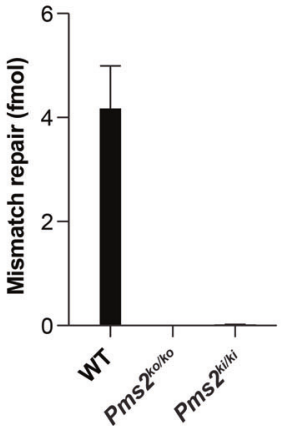

Fig. 4 Effect of Pms2 c.1993A>G variant on microsatellite instability (MSI) of polyps. Pattern of mononucleotide repeat markers A Bat37, B Bat59 in wild-type mouse colon DNA (control) and polyp DNA of Pms $2^{k i / k i}$ mice. Orange peaks show the size standards. Highest peak in control DNA is marked by dotted line. Number of nucleotides shifted is indicated on right. C Table showing the numbers of polyps with MSI in Bat37 and Bat59 locus of different genotypes. D MMR activity of nuclear extracts from MEFs of different genotypes. Top panel shows the schematic representation of the assay. Pst I site is impaired due to G-T mismatch in the nicked $\left(5^{\prime}\right.$ or $3^{\prime}$ to the mismatch) heteroduplex in which the thick line of inner strand represents unmethylated region. After incubating with nuclear extracts, heteroduplexes were digested with $P s t ~ I$ and Ase I. G-T mismatch repair on the Pst I site results into generation of smaller fragments (1.2 kb and $0.8 \mathrm{~kb})$ after Pst I and Ase I digestion. Middle panel shows the agarose gel electrophoresis of digested heteroduplexes or plasmids. Lower panel shows the quantification from three independent assays.

morpholino oligonucleotides have been also used in vivo in mouse models to downregulate protein levels in splenocytes [42]. Given the high prevalence of PMS2 c.2002A $>$ G founder GPV and the success of ASOs in targeting aberrant splicing, we sought to explore the possibility of using morpholinos for cancer prevention associated with this mutation. The relevance of this approach was supported by our ability to suppress the de novo splice site in primary fibroblasts generated from our mouse model as well as in fibroblasts generated from patient carrying homozygous PMS2 variant. Use of morpholinos restored expression of full-length 
A

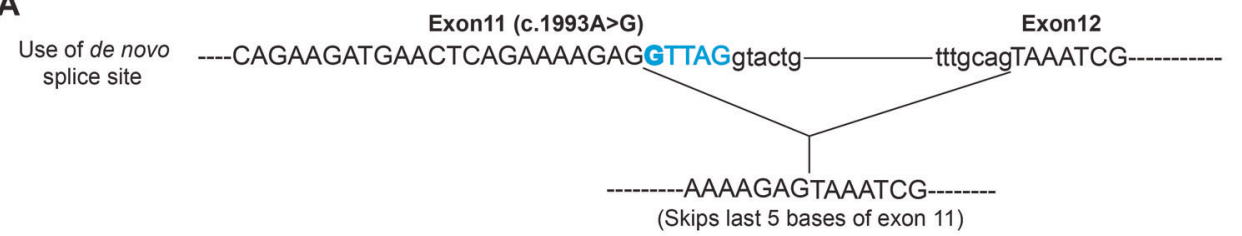

Suppression of de novo splice site by morpholino

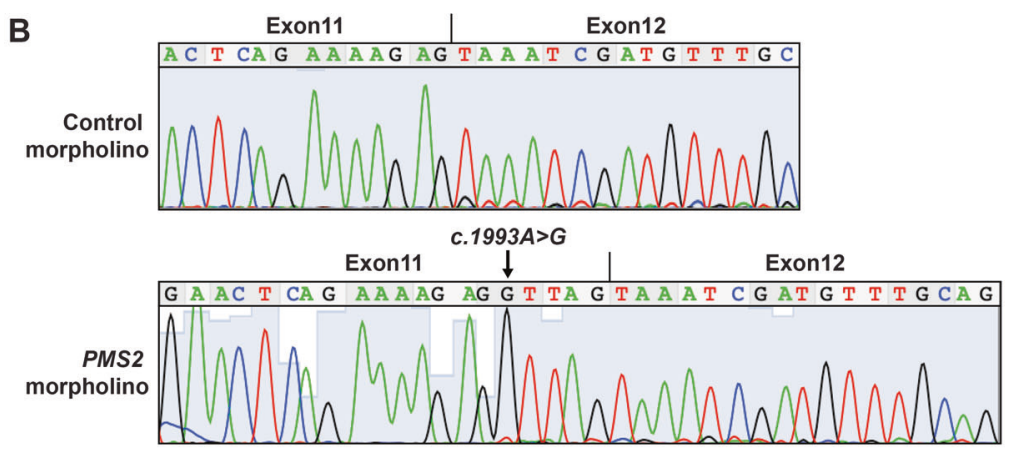

Fig. 5 Effect of morpholino on suppression of aberrant splicing of Pms2 c.1993A>G transcript. A Schematic representation of the use of morpholino to block the de novo splice site in Pms2 transcript with c.1993A>G mutation in exon 11. Uppercase letters mark the exon sequence and lowercase letters represent intronic sequence. 5 bases that are encoded by exon 11 and deleted in the transcript due to c.1993A $>$ G mutation are marked in blue. B Chromatogram showing the restoration of WT splice site in Pms $2^{k i / k i}$ mouse embryonic fibroblast (MEF) cells. MEFs were transfected either with $10 \mu \mathrm{M}$ control or Pms2 specific morpholino. Arrow marks the presence of c.1993A $>\mathrm{G}$ mutation in Pms2 transcript.

PMS2 in these cells. However, we did not observe any effect of these vivo-morpholinos when they were administered by IP or IV injections in our mouse model. Our inability to suppress aberrant splicing in the small intestine of mice suggests that although morpholinos can be effectively delivered to some tissues in mice and patients and used to treat some diseases, efficient delivery to other tissues such as the small intestine can be challenging at present [30, 32]. Future development of innovative delivery approaches may make it feasible to target morpholinos to the small intestine. Also, development of novel CRISPR-based genome editing approaches may open new avenues for suppressing aberrant transcript splicing. Having access to our preclinical mouse model will be of immense value in testing the efficacy of new strategies.

\section{METHODS \\ Reagents}

Antibodies used were PMS antibody (C-20) from Santa Cruz Biotechnology (1:1000 dilution; cat \# sc-618), PMS2 from BD Biosciences, Mississauga, Canada (1:500 dilution; cat \# 556415), GAPDH antibody from Abcam (1:50,000 dilution; cat \# ab9485), and SYCP3 antibody from Abcam (1:500 dilution; cat \# ab20244). All restriction endonucleases were purchased from New England Biolabs (Ipswich, MA, USA). Plasmid used in mismatch repair assay (pSCWO1) were obtained from Addgene (cat \# 72300). All control, fluorescent tagged and vivo-morpholino oligonucleotides ( 25 nucleotides in length), were purchased from Gene Tools, LLC (Corvallis, OR, USA). Morpholinos were designed complementary to the mutant splice site. Non-PMS2 controls were purchased from Gene Tools, LLC (Corvallis, OR, USA). Sequences for morpholinos used in human and mouse cells are $5^{\prime}$ ACCTCTITCTTAGTTCATCTTCGG $3^{\prime}$ and $5^{\prime}$ ACCTCTITCTGAGTTCAT CTTCTG $3^{\prime}$ respectively. All morpholinos except vivo-morpholinos were $3^{\prime}$ carboxyfluorescein labeled.

\section{Knock-in mouse generation}

The 9.5-kb fragment containing the region from $3^{\prime}$ part of intron 9 to $5^{\prime}$ part of intron 14 containing Pms2. $2^{c .1993 A>G}$ mutation in exon 11 was used to target V6.4 (129 X C57BL/6J) embryonic stem cells to generate the knock-in allele. The positive selection gene neor flanked by two loxP sites inserted into intron 11 of the Pms 2 gene in the targeting construct. Two BamHI sites were engineered on either side of the selection marker for screening of the targeted allele. A negative selection marker, herpes simplex thymidine kinase gene $(T K)$ was also inserted into the targeting construct (Supplementary Fig. 2A). The correctly targeted ES cells were screened by Southern hybridization of BamHI digested genomic DNA (Supplementary Fig. 2B, C). Presence of mutation was confirmed by sequencing of the PCR-amplified fragment (373 bp amplified using primers $5^{\prime}$ TAAGAGA ATCGTGCTCCTCG $3^{\prime}$ and $5^{\prime}$ CCACACTGGAGTCCTATTCC $3^{\prime}$ ) surrounding the mutated region (Supplementary Fig. 2D). Resulting chimeras from these ES cells successfully transmitted the mutated allele after breeding with WT mice in the C57BL/6J $\times 129 / \mathrm{Sv}$ mixed genetic background. All animal studies were performed as per the protocols outlined in the Guide for the Care and Use of Laboratory Animals and approved by the NCI-Frederick Animal Care and Use Committee.

\section{RNA isolation and RT-PCR}

Total RNA from frozen tissues was extracted using RNA-BEE (Tel-Test, Inc.) according to the manufacturer's protocol. Total RNA from cell lines was isolated either using the RNeasy mini kit (Qiagen, Cat\# 74104) or RNA-BEE (Tel-Test, Inc.).

RT-PCR analysis was performed using one-step RT-PCR kit (Qiagen) or by cDNA synthesis using Quantitech Reverse transcription Qiagen, kit \# 205311) according to the manufacturer's protocol. The primers from exon 11 (5' ATCAAGTCTAGGGGTCCAGAGACTGC $\left.3^{\prime}\right)$ and exon $14\left(5^{\prime}\right.$ TGGAAGCAAACATCTGTCTGACTCG $3^{\prime}$ ) of Pms2 were used for RT-PCR. The DNA amplified was gel purified (Qiagen) and sequenced. Amplified PCR products were visualized on agarose gel. Band intensity was quantified using the ImageJ software (http://rsbweb.nih.gov/ij/download.html). The 
A

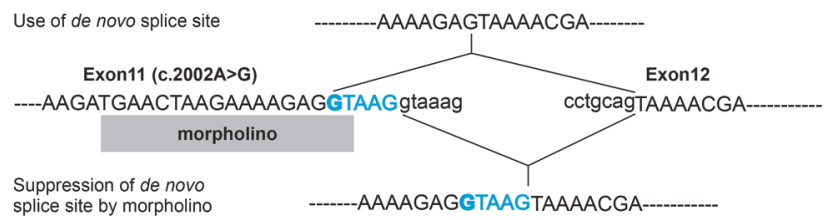

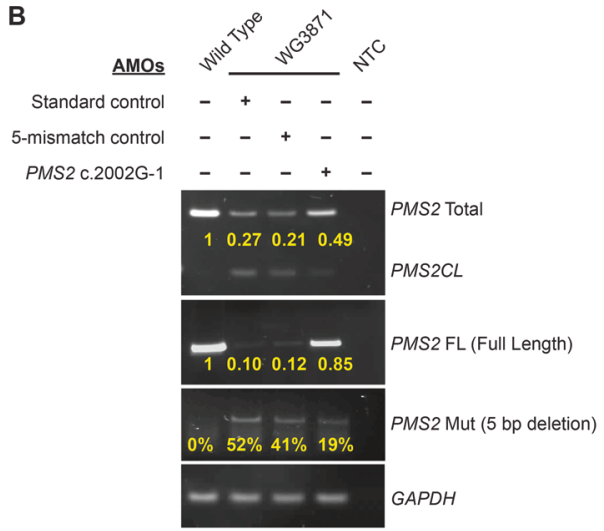

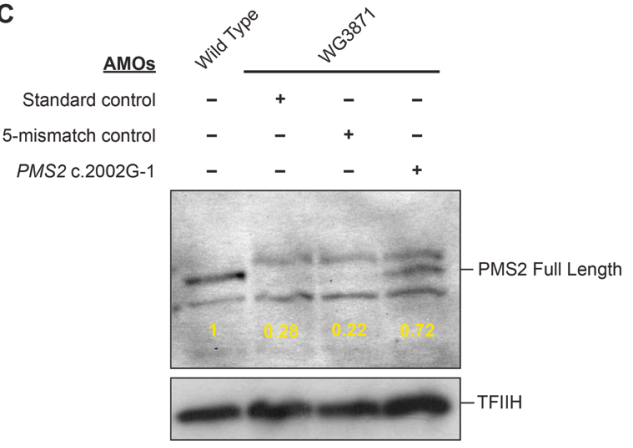

Fig. 6 PMS2 expression in morpholino-treated human cells with PMS2 c.2002A>G mutation. A Schematic representation of the splicing defect due to PMS2 c.2002A>G mutation and use of morpholinos to block the de novo splice site. Top panel shows use of de novo splice site and bottom panel shows restoration of normal splicing by morpholinos. Morpholino is represented as a rectangular box. Exons are marked by uppercase letters and introns are in lowercase letters. 5 bases encoded by exon 11 that are deleted in the transcript due to c.2002A $>G$ mutation are in blue and the mutation is in bold. B Quantitative PCR analysis of morpholino-treated cells shows an increase in the amount of full-length PMS2 transcript in cells treated with the PMS2 c.2002-1 AMO complementary to the novel splice site compared to cells treated with mismatched and non-PMS2 AMOs (negative controls). Treatment with the mutation-specific morpholino also results in an increase in total PMS2 transcript (full-length and aberrantly spliced). C Western blot showing levels of PMS2 protein in morpholino-treated cells. There is a clear increase in full-length PMS2 in cells treated with the mutation-specific morpholino compared to barely detectable levels of PMS2 in cells treated with the controls morpholinos. TFIIH is used as a loading control. Samples: wild-type =c.2002A/c.2002A genotype; WG3871 $=$ c.2002G/c.2002G genotype; NTC = no template control. AMOs: Standard control Morpholino specific to a region elsewhere in the genome, 5-Mismatch control Morpholino containing 5 mismatches compared to the PMS2 c.2002G-1 morpholino, PMS2 c.2002G-1 AMO morpholino complementary to the novel splice site created by the mutation.

primers used for RT-PCR analysis of morpholino-treated human fibroblasts are listed in Supplementary Table 3.

\section{Expression analysis}

Frozen tissues were homogenized and proteins were extracted using the extraction buffer $(50 \mathrm{~mm}$ Tris- $\mathrm{HCl}, \mathrm{pH} 7.4,1 \mathrm{~mm}$ ethylenediaminetetraacetic acid, $150 \mathrm{~mm} \mathrm{NaCl}, 0.1 \%$ sodium dodecyl sulfate, $1 \%$ Triton X-100, $0.25 \%$ sodium deoxycholate, $1 \mathrm{~mm}$ sodium fluoride, and $1 \mathrm{~mm}$ orthovanadate). Proteins were separated using NuPAGE $4-12 \%$ gradient gel (Invitrogen) or $7.5 \%$ acrylamide gel using electrophoresis for western blot analysis. ECL plus western blotting detection system (Amersham) or SuperSignal West Femto kit (Thermo Scientific, Rockford, United States) were used for chemiluminescent detection.

\section{Selection of sample sizes}

Sample sizes for animal studies were calculated using resource equation method. All analysis of animal studies results were done blindly.

\section{Histology}

Testes and polyps were fixed in 10\% neutral buffered formalin, dehydrated in ethanol, embedded in paraffin, serially sectioned, and stained with hematoxylin and eosin. Slides were examined using bright field microscopy.

\section{Spermatocyte spread preparation}

Spermatocyte spreads from the testes of mutant and control animals were prepared and stained as described previously [43].

\section{Microsatellite instability analysis}

PCR amplification of Bat24, Bat37, Bat59, and Bat64 was carried out using Taq polymerase (Invitrogen), with primer concentrations $0.1 \mu \mathrm{M}$. The thermal cycling conditions were as follows: initial denaturation at $95^{\circ}$
(Celsius) for $10 \mathrm{~min}$; followed by 40 cycles of $95^{\circ}$ for $45 \mathrm{~s}, 55^{\circ}$ for $45 \mathrm{~s}$, and $72^{\circ}$ for $1 \mathrm{~min}$; then a final extension step at $72^{\circ}$ for $5 \mathrm{~min}$. The dyes used for labeling the PCR products are FAM (Bat24), VIC (Bat37), NED (Bat59), and PET (Bat64). PCR fragments were separated by capillary electrophoresis in ABI3130XL (Life Technologies) and analyzed by using the GeneMapper program (Life Technologies). Primers used are listed in Supplementary Table 3.

\section{Mismatch repair assay}

Nuclear extracts from MEFs were prepared as described previously [44]. Briefly cell pellets collected from $4-5 \times 10^{8}$ cells were washed once with $40 \mathrm{ml}$ of cold hypotonic buffer $(20 \mathrm{mM}$ Hepes, $\mathrm{pH} 7.5 ; 5 \mathrm{mM} \mathrm{KCl} ; 0.5 \mathrm{mM}$ $\mathrm{MgCl}_{2} ; 0.1 \%$ PMSF; $2 \mathrm{mM} \mathrm{DTT;} 1 \mu \mathrm{g} / \mathrm{ml}$ of each aprotinin, leupeptin, pefabloc, and E-64 (Roche)) containing $0.2 \mathrm{M}$ sucrose. The cell pellet were then homozenized in $10 \mathrm{ml}$ cold hypotonic buffer without sucrose. The nuclear pellet obtained after centrifugation was resuspended in $2.5 \mathrm{ml}$ of extract buffer (50 mM Hepes, pH 7.5; $10 \%$ sucrose; 0.1\% PMSF; $2 \mathrm{mM}$ DTT; $1 \mu \mathrm{g} / \mathrm{ml}$ of each aprotinin, leupeptin, pefabloc, and E-64) and mixed on a rotator for $1 \mathrm{~h}$ after addition of $0.03 \mathrm{vol}$ of $5 \mathrm{M} \mathrm{NaCl}$. After centrifugation at $15,000 \times g$ for $30 \mathrm{~min}$, the supernatant was concentrated with an Amicon Ultracel-10K (Millipore).

sThe preparation of 5' G-T heteroduplex and 3' G-T heteroduplex DNAs and in vitro MMR assays were performed as described by Geng et al. [44]. The primers used for heteroduplex generation are listed in Supplementary Table 3. In brief, MMR assays were carried out using $75 \mathrm{fmol}(100 \mathrm{ng})$ of nicked pSCW01_GT DNA substrate, $100 \mu \mathrm{g}$ of nuclear extract, $0.1 \mathrm{mM}$ each of four dNTPs, in the standard MMR buffer $(20 \mathrm{mM}$ Tris- $\mathrm{HCl}, \mathrm{pH} 7.6 ; 1.5 \mathrm{mM}$ ATP; $1 \mathrm{mM}$ glutathione; $5 \mathrm{mM} \mathrm{MgCl}$; and $110 \mathrm{mM} \mathrm{NaCl}, 50 \mathrm{mg} / \mathrm{ml} \mathrm{BSA}$ ) for $15 \mathrm{~min}$ at $37^{\circ} \mathrm{C}$. The reaction was terminated by the addition of $80 \mu \mathrm{l}$ of stop solution ( $25 \mathrm{mM}$ EDTA, $0.67 \%$ sodium dodecyl sulfate, and $90 \mu \mathrm{g} / \mathrm{ml}$ proteinase K). DNA was extracted twice with phenol/chloroform and twice with chloroform and precipitated with 2.5 volume of ethanol. DNA was then dissolved in $\mathrm{H}_{2} \mathrm{O}$, and digested with 4 units each of Pstl and Asel 
endonuclease and $1 \mu \mathrm{g}$ of RNAase (Qiagen) at $37^{\circ} \mathrm{C}$ for $2 \mathrm{~h}$. DNA was then separated by electrophoresis on a $1.5 \%$ agarose gel. Quantification of DNA band was performed using Syngene genetools software.

\section{DATA AVAILABILITY}

The data that support the findings of this study are available from the corresponding author upon request.

\section{REFERENCES}

1. Li GM. Mechanisms and functions of DNA mismatch repair. Cell Res. 2008;18:85-98.

2. Germano G, Amirouchene-Angelozzi N, Rospo G, Bardelli A. The clinical impact of the genomic landscape of mismatch repair-deficient cancers. Cancer Discov. 2018;8:1518-28.

3. Wimmer $\mathrm{K}$, Kratz $\mathrm{CP}$, Vasen HF, Caron $\mathrm{O}$, Colas $\mathrm{C}$, Entz-Werle $\mathrm{N}$, et al. Diagnostic criteria for constitutional mismatch repair deficiency syndrome: suggestions of the European consortium 'care for CMMRD' (C4CMMRD). J Med Genet. 2014;51:355-65.

4. Kasela M, Nystrom M, Kansikas M. PMS2 expression decrease causes severe problems in mismatch repair. Hum Mutat. 2019;40:904-7.

5. Reyes GX, Schmidt TT, Kolodner RD, Hombauer $H$. New insights into the mechanism of DNA mismatch repair. Chromosoma. 2015;124:443-62.

6. Cannavo E, Marra G, Sabates-Bellver J, Menigatti M, Lipkin SM, Fischer F, et al. Expression of the MutL homologue hMLH3 in human cells and its role in DNA mismatch repair. Cancer Res. 2005;65:10759-66.

7. Korhonen MK, Raevaara TE, Lohi H, Nystrom M. Conditional nuclear localization of hMLH3 suggests a minor activity in mismatch repair and supports its role as a low-risk gene in HNPCC. Oncol Rep. 2007;17:351-4.

8. Svrcek M, Lascols $O$, Cohen R, Collura $A$, Jonchère V, Fléjou JF, et al. MSI/MMRdeficient tumor diagnosis: which standard for screening and for diagnosis? Diagnostic modalities for the colon and other sites: differences between tumors. Bull Cancer. 2019;106:119-28.

9. Li L, Hamel N, Baker K, McGuffin MJ, Couillard M, Gologan A, et al. A homozygous PMS2 founder mutation with an attenuated constitutional mismatch repair deficiency phenotype. J Med Genet. 2015;52:348-52.

10. Lee $\mathrm{K}$, Tosti E, Edelmann W. Mouse models of DNA mismatch repair in cancer research. DNA Repair. 2016;38:140-6.

11. Baker SM, Bronner CE, Zhang L, Plug AW, Robatzek M, Warren G, et al. Male mice defective in the DNA mismatch repair gene PMS2 exhibit abnormal chromosome synapsis in meiosis. Cell. 1995;82:309-19.

12. Prolla TA, Baker SM, Harris AC, Tsao JL, Yao X, Bronner CE, et al. Tumour susceptibility and spontaneous mutation in mice deficient in Mlh1, Pms1 and Pms2 DNA mismatch repair. Nat Genet. 1998;18:276-9.

13. Narayanan L, Fritzell JA, Baker SM, Liskay RM, Glazer PM. Elevated levels of mutation in multiple tissues of mice deficient in the DNA mismatch repair gene Pms2. Proc Natl Acad Sci USA. 1997;94:3122-7.

14. Yao X, Buermeyer AB, Narayanan L, Tran D, Baker SM, Prolla TA, et al. Different mutator phenotypes in Mlh1- versus Pms2-deficient mice. Proc Natl Acad Sci USA. 1999;96:6850-5.

15. Baker SM, Harris AC, Tsao JL, Flath TJ, Bronner CE, Gordon M, et al. Enhanced intestinal adenomatous polyp formation in Pms2-/-; Min mice. Cancer Res. 1998;58:1087-9.

16. Huang J, Zheng S, Jin SH, Zhang SZ. Somatic mutations of APC gene in carcinomas from hereditary non-polyposis colorectal cancer patients. World J Gastroenterol. 2004;10:834-6.

17. Salahshor S, Kressner U, Pâhlman L, Glimelius B, Lindmark G, Lindblom A. Colorectal cancer with and without microsatellite instability involves different genes. Genes Chromosomes Cancer. 1999;26:247-52.

18. van Oers JM, Roa S, Werling U, Liu Y, Genschel J, Hou H Jr, et al. PMS2 endonuclease activity has distinct biological functions and is essential for genome maintenance. Proc Natl Acad Sci USA. 2010;107:13384-9.

19. Cartegni L, Wang J, Zhu Z, Zhang MQ, Krainer AR. ESEfinder: A web resource to identify exonic splicing enhancers. Nucleic Acids Res. 2003;31:3568-71.

20. Fodde R, Edelmann W, Yang K, van Leeuwen C, Carlson C, Renault B, et al. A targeted chain-termination mutation in the mouse Apc gene results in multiple intestinal tumors. Proc Natl Acad Sci USA. 1994;91:8969-73.

21. Oshima $M$, Oshima $H$, Kitagawa $K$, Kobayashi $M$, Itakura $C$, Taketo $M$. Loss of Apc heterozygosity and abnormal tissue building in nascent intestinal polyps in mice carrying a truncated Apc gene. Proc Natl Acad Sci USA. 1995;92:4482-6.

22. Su LK, Kinzler KW, Vogelstein B, Preisinger AC, Moser AR, Luongo C, et al. Multiple intestinal neoplasia caused by a mutation in the murine homolog of the APC gene. Science. 1992;256:668-70.
23. Yang K, Edelmann W, Fan K, Lau K, Kolli VR, Fodde R, et al. A mouse model of human familial adenomatous polyposis. J Exp Zool. 1997;277:245-54.

24. Edelmann W, Yang K, Kuraguchi M, Heyer J, Lia M, Kneitz B, et al. Tumorigenesis in Mlh1 and Mlh1/Apc1638N mutant mice. Cancer Res. 1999;59:1301-7.

25. Kuraguchi M, Edelmann W, Yang K, Lipkin M, Kucherlapati R, Brown AM. Tumorassociated Apc mutations in Mlh1-/- Apc1638N mice reveal a mutational signature of Mlh1 deficiency. Oncogene. 2000;19:5755-63.

26. Kuraguchi M, Yang K, Wong E, Avdievich E, Fan K, Kolodner RD, et al. The distinct spectra of tumor-associated Apc mutations in mismatch repair-deficient Apc1638N mice define the roles of MSH3 and MSH6 in DNA repair and intestinal tumorigenesis. Cancer Res. 2001;61:7934-42.

27. Soravia C, DeLozier CD, Dobbie Z, Berthod CR, Arrigoni E, Bründler MA, et al. Double frameshift mutations in APC and $\mathrm{MSH} 2$ in the same individual. Int J Colorectal Dis. 2005;20:466-70.

28. Currey N, Daniel JJ, Mladenova DN, Dahlstrom JE, Kohonen-Corish MRJ. Microsatellite instability in mouse models of colorectal cancer. Can J Gastroenterol Hepatol. 2018;2018:6152928.

29. Deschênes SM, Tomer G, Nguyen M, Erdeniz N, Juba NC, Sepúlveda N, et al. The E705K mutation in hPMS2 exerts recessive, not dominant, effects on mismatch repair. Cancer Lett. 2007;249:148-56.

30. Li D, Adams AM, Johnsen RD, Fletcher S, Wilton SD. Morpholino oligomerinduced dystrophin isoforms to map the functional domains in the dystrophin protein. Mol Ther Nucleic Acids. 2020;22:263-72.

31. Morcos PA, Li Y, Jiang S. Vivo-Morpholinos: a non-peptide transporter delivers Morpholinos into a wide array of mouse tissues. Biotechniques. 2008;45:613-4.

32. Wu B, Li Y, Morcos PA, Doran TJ, Lu P, Lu QL. Octa-guanidine morpholino restores dystrophin expression in cardiac and skeletal muscles and ameliorates pathology in dystrophic mdx mice. Mol Ther. 2009;17:864-71.

33. Scotti MM, Swanson MS. RNA mis-splicing in disease. Nat Rev Genet. 2016;17:19-32.

34. Escobar-Hoyos L, Knorr K, Abdel-Wahab O. Aberrant RNA splicing in cancer. Annu Rev Cancer Biol. 2019;3:167-85.

35. Fischer JM, Dudley S, Miller AJ, Liskay RM. An intact Pms2 ATPase domain is not essential for male fertility. DNA Repair. 2016;39:46-51.

36. Qin X, Shibata D, Gerson SL. Heterozygous DNA mismatch repair gene PMS2knockout mice are susceptible to intestinal tumor induction with $\mathrm{N}$-methyl-Nnitrosourea. Carcinogenesis. 2000;21:833-8.

37. Lu QL, Rabinowitz A, Chen YC, Yokota T, Yin H, Alter J, et al. Systemic delivery of antisense oligoribonucleotide restores dystrophin expression in body-wide skeletal muscles. Proc Natl Acad Sci USA. 2005;102:198-203.

38. Yokota T, Lu QL, Partridge T, Kobayashi M, Nakamura A, Takeda S, et al. Efficacy of systemic morpholino exon-skipping in Duchenne dystrophy dogs. Ann Neurol. 2009;65:667-76.

39. Guncay A, Yokota T. Antisense oligonucleotide drugs for Duchenne muscular dystrophy: how far have we come and what does the future hold? Future Med Chem. 2015;7:1631-5.

40. Touznik A, Lee JJ, Yokota T. New developments in exon skipping and splice modulation therapies for neuromuscular diseases. Expert Opin Biol Ther. 2014;14:809-19.

41. Dowling JJ. Eteplirsen therapy for Duchenne muscular dystrophy: skipping to the front of the line. Nat Rev Neurol. 2016;12:675-6.

42. Chandrakar P, Seth A, Rani A, Dutta M, Parmar N, Descoteaux A, et al. Jagged/ Notch-mediated divergence of immune cell crosstalk maintains antiinflammatory response in visceral leishmaniasis. J Cell Sci. 2021;134:jcs252494.

43. Romanienko PJ, Camerini-Otero RD. The mouse Spo11 gene is required for meiotic chromosome synapsis. Mol Cell. 2000;6:975-87.

44. Geng H, Du C, Chen S, Salerno V, Manfredi C, Hsieh P. In vitro studies of DNA mismatch repair proteins. Anal Biochem. 2011;413:179-84.

\section{ACKNOWLEDGEMENTS}

We thank members of our laboratory for helpful discussions and suggestions. We thank Dr. Sounak Sahu for his comments and critical review of the manuscript. We thank Todd B. Young and Heidi E. Lawhorn of the CLIA Molecular Diagnostics Laboratory of FNLCR for their help with microsatellite instability testing. We thank Joseph Meyer of the Scientific Publications, Graphics and Media Dept of NCI-Frederick for help with figures. This work was funded in a part by a grant from the Canadian Cancer Society (\#002569) to W.D.F. The research is supported by the Intramural Research Program, Center for Cancer Research, U.S. National Cancer Institute (L.T., and S.K.S.).

\section{AUTHOR CONTRIBUTIONS}

S.K.S. and W.D.F. conceived the project. K.B., M.C., and S.S. generated the PMS2 knockin targeting construct. E.S., S.R., and L.T. generated the knock-in mice. M.C., L.C., and N.H. performed the morpholino studies in human fibroblast. K.B. performed all experiments with the mouse model. B.K.M. and M.E.A. assisted in animal studies. 
C.M.-K. and V.M. performed histopathological analysis. S.B., T.M.P., R.N.B., S.D.M., and K.M.P. performed M.S.I. analysis. K.B., W.D.F., and S.K.S. analyzed and interpreted the data and wrote the manuscript. All authors commented on the manuscript.

\section{FUNDING}

Open Access funding provided by the National Institutes of Health $(\mathrm{NIH})$.

\section{COMPETING INTERESTS}

The authors declare no competing interests.

\section{ADDITIONAL INFORMATION}

Supplementary information The online version contains supplementary material available at https://doi.org/10.1038/s41419-021-04130-8.

Correspondence and requests for materials should be addressed to Shyam K. Sharan.

Reprints and permission information is available at http://www.nature.com/reprints
Publisher's note Springer Nature remains neutral with regard to jurisdictional claims in published maps and institutional affiliations.

(i) Open Access This article is licensed under a Creative Common Attribution 4.0 International License, which permits use, sharing, adaptation, distribution and reproduction in any medium or format, as long as you give appropriate credit to the original author(s) and the source, provide a link to the Creative Commons license, and indicate if changes were made. The images or other third party material in this article are included in the article's Creative Commons license, unless indicated otherwise in a credit line to the material. If material is not included in the article's Creative Commons license and your intended use is not permitted by statutory regulation or exceeds the permitted use, you will need to obtain permission directly from the copyright holder. To view a copy of this license, visit http://creativecommons. org/licenses/by/4.0/.

This is a U.S. government work and not under copyright protection in the U.S.; foreign copyright protection may apply 2021 